\title{
Identification of a Histamine Release Inhibitory Factor Produced by Human Mononuclear Cells In Vitro
}

\author{
Rafeul Alam, J. Andrew Grant, and Michael A. Lett-Brown \\ Allergy Division, Department of Internal Medicine, University of Texas Medical Branch at Galveston, Galveston, Texas 77550
}

\begin{abstract}
Human mononuclear cells (MNC) secrete histamine-releasing factor(s) (HRF) when cultured in vitro. HRF induces the release of histamine and other mediators from basophils and mast cells. We have shown that MNC also produce a histamine release inhibitory factor (HRIF), and that the synthesis is augmented by culture with physiologic concentrations of histamine $\left(10^{-10}\right.$ to $\left.10^{-6} \mathrm{M}\right)$ and by the mitogen concanavalin $A$ (Con A). HRIF does not affect release initiated by other secretagogues such as allergen, anti-IgE, C5a, Con A, and phorbol myristate acetate. HRIF requires a preincubation with the cells for 5-10 min for maximal inhibition, and this effect is not abolished by washing the cells after the preincubation. The biological activity of HRIF is protease-sensitive, neuraminidase-resistant, and relatively heat-stable. HRIF can be distinguished from HRF by a lower apparent molecular mass (8,000-10,000 D).
\end{abstract}

\section{Introduction}

A complex network of interactions exists between the immunoregulatory cells (lymphocytes and monocytes) and the primary effector cells of allergic reactions (mast cells and basophils). Lymphocytes produce interleukin 3 (IL-3), a pluripotent colony-stimulating factor that stimulates the growth of mast cells and basophils (1). IL-4 acts as an auxiliary factor in the growth of mast cells (2). It has been claimed that another cytokine, basophil growth factor, selectively stimulates the growth and differentiation of basophils (3). Lymphocytes also affect the function of these cells. B cells produce IgE antibodies, which bind to the high-affinity receptors on the surface of the mast cells and basophils and arm them for specific effector function.

Dvorak and his associates (4) were the first to postulate that lymphocytes might directly activate mast cells and basophils in delayed hypersensitivity reactions. Subsequently, it has been shown that mononuclear cells, lymphocytes, and pulmonary macrophages produce histamine-releasing factors (HRF) ${ }^{1}$ that activate human mast cells and basophils with increased di-

\footnotetext{
Address reprint requests to Dr. Alam, University of Texas Medical Branch, Route G-62, Galveston, TX 77550.

Received for publication 12 January 1988 and in revised form 12 July 1988.
}

1. Abbreviations used in this paper: $\mathrm{HRF}$, histamine-releasing factor(s); HRIF, histamine release inhibitory factor; MNC, mononuclear cells.

J. Clin. Invest.

(c) The American Society for Clinical Investigation, Inc. 0021-9738/88/12/2056/07 \$2.00

Volume 82, December 1988, 2056-2062 rected migration and release of histamine and leukotrienes (5-9). Another group of lymphokines has been identified in rodents that specifically binds to antigens and releases serotonin from mast cells (10). Thus, it is apparent that immunoregulatory cells produce a number of substances that stimulate the growth and function of mast cells and basophils.

Analysis of the regulatory mechanisms of the immune system reveals that they often function in a dichotomous fashion. For instance, growth stimulatory factors (e.g., IL-1-4, colonystimulating factors) are opposed by growth inhibitory cytokines (e.g., soluble immune response suppressor, inhibitor of DNA synthesis, inhibitor of colony formation, and inhibitor of IL-2) (11-14). The activity of chemotactic factors is abrogated by migration inhibitory factors (15). The production of IgE is regulated by two opposing factors: IgE potentiating factor and IgE suppressive factor (16).

These observations support the conclusion that lymphocytic regulation of effector cells comprises two loops: stimulatory and inhibitory. In the case of mast cells and basophils, only the stimulatory loop has been identified. Therefore, we asked whether mononuclear cells (MNC) produce cytokines that inhibit the function of mast cells and basophils. Recently, the production of a histamine release inhibitory factor (HRIF) by guinea pig lymphoid cells has been reported by one of us (17). This cytokine blocks histamine release from guinea pig mast cells and basophils. The present study was undertaken to investigate whether human lymphocytes produce a similar inhibitory factor.

It is clear that histamine is a major factor in allergic inflammation. This substance also has important immunomodulatory effects. Some of its actions include immunosuppressive effects such as stimulating the synthesis of inhibitory lymphokines (18). Therefore, we investigated whether histamine might stimulate the synthesis of HRIF by human MNC.

\section{Methods}

Reagents. RPMI 1640 was obtained from Gibco, Grand Island, NY; human serum albumin, glutamine, 2-mercaptoethanol, histamine, phorbol myristate acetate (PMA), Ficoll, Hypaque, concanavalin A (Con A), penicillin, streptomycin and agarose-coupled trypsin, chymotrypsin, and neuraminidase from Sigma Chemical Co., St. Louis, MO; Hepes from Research Organics, Inc., Cleveland, $\mathrm{OH}$; tissue culture flasks from Corning Glass Works, Corning, NY; Sephadex G-50 superfine from Pharmacia, Inc., Piscataway, NJ; hydroxyethyl starch (HetaStarch) from American McGaw, Irvine, CA; Spectrapor dialysis tubing from Spectrum Medical Industries, Los Angeles, CA; rabbit anti-human IgE serum was from Behring Diagnostics, Somerville, NY; ragweed pollen allergen from Greer, Lenoir, NC. C5a was obtained by the method described previously (19).

Isolation of MNC. Peripheral venous blood $(40-60 \mathrm{ml})$ was drawn from healthy donors after obtaining written informed consent. Heparinized blood was diluted with 2 vol of Hanks' balanced salt solution (HBSS) and centrifuged on a Ficoll-Hypaque (specific gravity 1.077) 
cushion. MNC were separated and washed three times with HBSS and suspended at a concentration $5 \times 10^{6} / \mathrm{ml}$ in RPMI 1640 medium containing $100 \mathrm{U}$ penicillin/ml, $100 \mu \mathrm{g}$ streptomycin/ml, $4 \mathrm{mM}$ glutamine, and $5 \times 10^{-6} \mathrm{M} 2$-mercaptoethanol.

Generation of HRIF-containing supernatants. MNC were cultured ( $10 \mathrm{ml}$ of cell suspension in a $25-\mathrm{cm}^{2}$ tissue culture flask) in the absence or presence of various concentrations of histamine for $24 \mathrm{~h}$ at $37^{\circ} \mathrm{C}$ in a humidified incubator. Supernatants were harvested by centrifugation and extensively dialyzed against sterile water (usually $2 \times 1,000 \mathrm{vol}$ ) and Hepes buffer, pH $7.4(10 \mathrm{mM}$ Hepes, $137 \mathrm{mM} \mathrm{NaCl}$, and $5 \mathrm{mM}$ $\mathrm{KCl}$ ) containing $2 \mathrm{mM} \mathrm{CaCl}{ }_{2}$ and $1 \mathrm{mM} \mathrm{MgCl}_{2}$ (HCM buffer) to completely remove histamine. Spectrapor dialysis tubing with a $M_{\mathrm{r}}$ cutoff of 3,500 D was used for routine dialysis. The dialyzed supernatants were used immediately or stored at $-70^{\circ} \mathrm{C}$.

Generation of Con A-conditioned medium and separation of $H R F$ by gel filtration. Leukocytes were isolated from buffy coats obtained from normal blood bank donors. MNC were isolated as described earlier and pulsed with Con $\mathrm{A}(25 \mu \mathrm{g} / \mathrm{ml})$ in RPMI medium for $4 \mathrm{~h}$, washed twice with HBSS, resuspended in RPMI medium, and cultured for $72 \mathrm{~h}$. The supernatants were harvested, dialyzed, and assayed for both HRF and HRIF as described below.

In other experiments supernatant fluid was concentrated $\times 50$ by using an ultrafiltration chamber (Amicon Corp., Danvers, MA) with YM-5 filters (mol wt cutoff 5,000). Usually supernatants were pooled from cultured MNC obtained from 10-15 liters of blood and concentrated, and $20-30 \mathrm{ml}$ of this sample was then applied to gel filtration columns $(5 \times 100 \mathrm{~cm})$ containing Sephadex G-75. Fractions containing histamine-releasing activity (15-30-kD fractions), measured as described below, were pooled, concentrated 10 -fold, divided into aliquots, frozen at $-70^{\circ} \mathrm{C}$, and used as a source of HRF.

Isolation of peripheral blood leukocytes. Venous blood from allergic donors was anticoagulated with $10 \mathrm{mM}$ EDTA and sedimented with $1.5 \%$ hydroxyethyl starch for $30 \mathrm{~min}$ at room temperature. The leukocyte-rich buffy coat was collected and washed three times in Hepes buffer, $\mathrm{pH} 7.4$ and $0.03 \%$ human serum albumin (HA buffer) in a refrigerated centrifuge $\left(4^{\circ} \mathrm{C}\right)$ at $300 \mathrm{~g}$. The washed leukocytes (0.1-1\% basophils) were suspended in Hepes buffer, $\mathrm{pH} 7.4,0.03 \%$ human serum albumin, $2 \mathrm{mM} \mathrm{CaCl}$, and $1 \mathrm{mM} \mathrm{MgCl}$ (HACM buffer). Leukocytes from $1 \mathrm{ml}$ of blood were usually used for one duplicate experiment for assaying HRF and HRIF.

Assay of $H R F$. Aliquots of $100 \mu \mathrm{l}$ of test supernatant were incubated with $100 \mu$ l of leukocyte suspension for $45 \mathrm{~min}$ in a shaking water bath at $37^{\circ} \mathrm{C}$. Each experiment was done in duplicate. At the end of the incubation, $400 \mu \mathrm{l}$ of HA buffer were added to each tube. The supernatants were separated from the cells by centrifugation at $600 \mathrm{~g}$ for $5 \mathrm{~min}$ at $4^{\circ} \mathrm{C}$. The histamine content of the supernatants was measured using an automated fluorometric analyzer (20). Spontaneous histamine release was assessed by incubating the cells in HACM buffer alone. The total histamine content of the cells was measured by lysing the cells with $3 \%$ perchloric acid. The percentage of histamine release was calculated according to the formula: (histamine in the supernatant)/(total histamine in the cells) $\times 100$.

Spontaneous histamine release from the cells was usually $<5 \%$ and was subtracted from the calculated histamine release.

Assay of HRIF. Aliquots of $100 \mu \mathrm{l}$ of diluted test supernatants were preincubated with $100 \mu \mathrm{l}$ of leukocyte suspension for $5 \mathrm{~min}$ at $37^{\circ} \mathrm{C}$ and then challenged with $100 \mu \mathrm{l}$ of HRF-containing supernatant for an additional $45 \mathrm{~min}$ at $37^{\circ} \mathrm{C}$. Three sets of controls were run simultaneously: $(i)$ cells preincubated with buffer and then challenged with HRF, (ii) cells preincubated with the test supernatant and then challenged with buffer, and (iii) cells preincubated with buffer and challenged with buffer.

Each experiment was performed in duplicate. At the conclusion of the incubation, $300 \mu \mathrm{l}$ of HACM buffer were added to each tube, and the supernatants were separated from the cells by centrifugation at 600 $g$ for $5 \mathrm{~min}$ at $4^{\circ} \mathrm{C}$. The histamine content of the supernatants was measured spectrofluorometrically (20). The percentage of histamine released was calculated as described above.
A typical experiment was carried out according to the following protocol:

Preincubation Challenge

(a) leukocytes + buffer

+ buffer

(b) leukocytes + buffer

(c) leukocytes + supernatant

+ HRF

(d) leukocytes + supernatant

+ buffer

$+\mathrm{HRF}$

The percentage of inhibition of histamine release was calculated according to the formula: $[(b-a)-(d-c)] \times 100 /(b-a)$.

The dilution of HRF for these experiments was so chosen as to obtain a histamine release in the range of 20 to $50 \%$.

Gel filtration of HRIF containing supernatant. Chromatography was performed with a column $(90 \times 1.5 \mathrm{~cm})$ packed with Sephadex G-50 and equilibrated with HCM buffer. The column was calibrated with blue dextran, carbonic anhydrase, cytochrome $c$ and insulin. Flow rate was maintained at $12 \mathrm{ml} / \mathrm{h}$ at $4^{\circ} \mathrm{C}$. Usually $2 \mathrm{ml}$ of concentrated $(\times 10-15)$ supernatant was applied to the column. Fractions of $1 \mathrm{ml}$ were collected and assayed for HRF and HRIF activity.

Enzymatic treatment of HRIF-containing supernatant. Trypsin and chymotrypsin coupled to agarose were washed twice with HCM, pH 7.8, and suspended in the same buffer. Aliquots of HRIF-containing supernatants from histamine-stimulated MNC cultures were dialyzed against $\mathrm{HCM}, \mathrm{pH} 7.8$, and then incubated with trypsin $(2 \mathrm{U} / \mathrm{ml})$ or chymotrypsin $(2 \mathrm{U} / \mathrm{ml})$ for $2 \mathrm{~h}$ at $30^{\circ} \mathrm{C}$. Neuraminidase coupled to agarose was washed with acetate buffer, $\mathrm{pH} 5.0$, and then incubated for $2 \mathrm{~h}$ at $37^{\circ} \mathrm{C}$ at a concentration of $2 \mathrm{U} / \mathrm{ml}$ with HRIF dialyzed against the same buffer. Controls included supernatants treated with the same buffers (positive control) and agarose-coupled enzymes incubated with buffer (negative control). Supernatants were separated from the enzymes by centrifugation, dialyzed against HCM buffer ( $\mathrm{pH} 7.4)$ and assayed for HRIF.

Affinity chromatography. Aliquots of $1 \mathrm{ml}$ of histamine- or Con A-stimulated supernatants were incubated with $0.5 \mathrm{ml}$ of washed lentil lectin-coupled Sepharose for $90 \mathrm{~min}$ at room temperature as described by Yodoi et al. (21). After removal of the effluent and washing with 4 $\mathrm{ml}$ of HCM buffer, the beads were eluted with $4 \mathrm{ml}$ of $0.2 \mathrm{M} \alpha$-methylmannoside at $4^{\circ} \mathrm{C}$. For peanut agglutinin-agarose chromatography, aliquots of $1 \mathrm{ml}$ of the supernatants were mixed with $0.15 \mathrm{ml}$ of the washed packed gel at $4^{\circ} \mathrm{C}$ for $4 \mathrm{~h}(21)$. The effluent was removed, and the beads were washed with $4 \mathrm{ml}$ of HCM and then $4 \mathrm{ml}$ of $0.2 \mathrm{M}$ D-galactose in HCM buffer, $\mathrm{pH}$ 7.4. All fractions were dialyzed against HCM buffer and then assayed for HRF and HRIF activity.

Statistical analysis. Results are expressed as mean \pm SEM. Data were analyzed for differences using the computer program EPISTAT.

\section{Results}

Effect of histamine on synthesis of HRF. We have previously reported that human MNC release small amounts of HRF spontaneously. In our preliminary experiments we examined the effect of histamine on this production. Cells from 10 healthy donors were cultured with or without histamine $\left(10^{-8}\right.$ M) and unconcentrated supernatants were assayed for histamine release from fresh basophils. The amount of histamine released by supernatants from cell cultured with and without histamine was $3 \pm 1 \%$ and $9 \pm 1 \%$, respectively, and the difference was significant $(P<0.001$, Student's $t$ test). We speculated that histamine-stimulated supernatant might contain an inhibitor of histamine release. Therefore, we examined whether the supernatants could inhibit release of histamine from peripheral blood basophils.

Stimulation of HRIF synthesis by histamine. First we in- 
vestigated the effect on the secretion initiated by HRF. We observed that supernatant from histamine-stimulated MNC inhibited histamine release from heterologous basophils by HRF (Fig. 1). MNC cultured alone showed modest inhibitory activity, but histamine-stimulated supernatant showed signifcantly $(P<0.001$, Wilcoxon's rank sum test) higher activity. The action of this HRIF obtained from six consecutive cell donors was dose-dependent over a wide range of dilutions. Histamine incubated with medium alone and then dialyzed did not show any inhibitory activity. Histamine was undetectable in all these dialyzed supernatants.

The production of HRIF depended on the dose of histamine used in the culture. The highest production of HRIF was usually noted at a concentration $10^{-6}$ to $10^{-8} \mathrm{M}$ (Fig. 2), although we observed considerable individual variation.

Over the last $1 \frac{1}{2}$ yr we have examined the production of HRIF by histamine-stimulated MNC obtained from 30 normal donors and obtained significant activity from $80 \%$ of the donors in response to at least one concentration of histamine.

Effect of Con A on both HRF and HRIF. Since Con A is a nonspecific mitogen and stimulates various subpopulations of MNC (e.g., helper and suppressor $T$ cells), we reasoned that Con A-stimulated supernatant might contain both HRF and HRIF activities. Therefore, we assayed net histamine release by unstimulated and Con A-stimulated supernatants obtained from culturing MNC of four normal donors as well as the effect of these supernatants on HRF-induced histamine release from basophils. As shown in Fig. 3, unstimulated supernatants released small amounts of histamine at high concentrations but showed significant inhibition of HRF-induced histamine release in a dose-dependent manner $(P<0.05$ by Wilcoxon's rank sum test for dilutions 1:12 to 1:3). Con A-stimulated MNC supernatant released significantly more histamine at dilutions $1: 12$ to $1: 3(P<0.05$ by Wilcoxon's rank sum test as

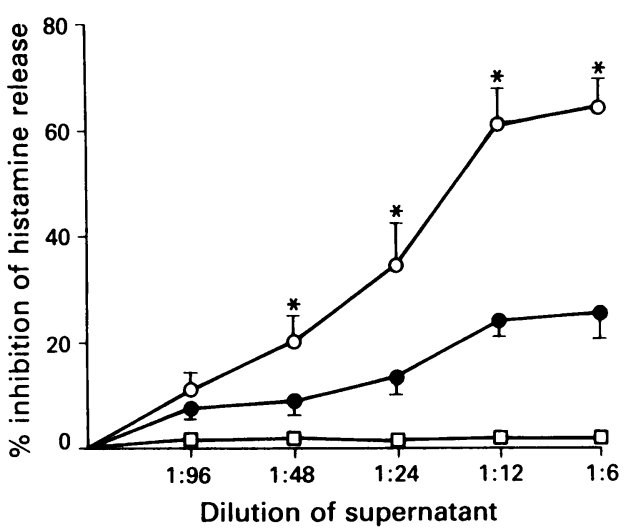

Figure 1. Production of HRIF by histamine-stimulated MNC culture supernatant. MNC from six healthy donors were cultured in RPMI either alone $(\bullet)$ or in the presence of histamine $\left(10^{-8} \mathrm{M}\right)(0)$ for $24 \mathrm{~h}$. Culture supernatant was harvested by centrifugation, dialyzed twice against 1,000 vol of water and 100 vol of HCM buffer to remove histamine, and tested for inhibition of HRF-induced histamine release from basophils obtained from three allergic donors. HRF-induced histamine release ranged from $25 \%$ to $44 \%$. Data are expressed as mean \pm SEM. Unstimulated MNC cultured in RPMI spontaneously produced some HRIF and this production was significantly enhanced in the presence of histamine $\left({ }^{*} P<0.001\right.$, Wilcoxon's rank sum test). Histamine cultured without MNC ( $\square$ ) had no inhibitory activity.

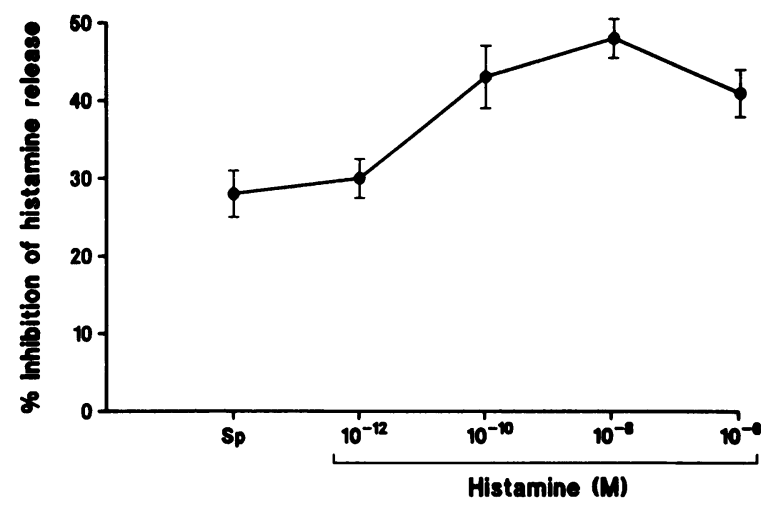

Figure 2. Dose-dependent stimulation of HRIF production by histamine. MNC from five healthy donors were stimulated with various concentrations of histamine. Dialyzed supernatants (1:6 final dilution) were tested for the inhibition of HRF-induced histamine release from basophils obtained from one allergic donor. HRF-induced histamine release was $40 \%$. The $P$ values (Wilcoxon's rank sum test) for the difference between the spontaneous production $(S p)$ and histamine-stimulated productions are as follows: $P>0.5$ for histamine $10^{-12} \mathrm{M}, P=0.01$ for histamine $10^{-10} \mathrm{M}, P=0.007$ for histamine $10^{-8} \mathrm{M}$, and $P=0.03$ for histamine $10^{-6} \mathrm{M}$.

compared to the release by unstimulated supernatants). However the same supernatant showed marked inhibition of histamine release at higher dilutions $(P<0.05$ by Wilcoxon's rank sum test for dilutions 1:96 to 1:12). The difference in the inhibition of HRF-induced histamine release by Con A-superna-

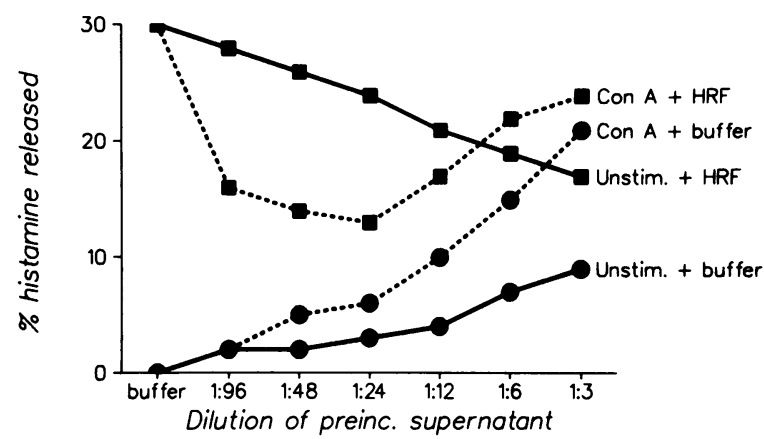

Figure 3. MNC from four healthy donors were cultured alone (-) or in the presence of Con A $(25 \mu \mathrm{g} / \mathrm{ml},---)$, and the dialyzed supernatants were assayed for direct histamine release $(\bullet)$ and for their effect on HRF-induced histamine release ( $\square$ ) from basophils of a single donor. Con A-containing supernatants were assayed in the presence of $0.05 \mathrm{M} \alpha$-methylmannoside to counteract the direct histamine-releasing effect of this lectin. Basophils were preincubated with the supernatants for $5 \mathrm{~min}$ and then challenged with buffer or HRF. In control experiments, cells were preincubated with buffer followed by HRF challenge (buffer + HRF). Results are mean of four duplicate experiments. SEM ranged from 0.4 to 2.5 and were omitted for clarity. Statistically significant differences $(P<0.05$, Wilcoxon's rank sum test) were obtained for following variables: $(i)$ Con A-supernatant (Con A + buffer) vs. unstimulated supernatant (Unstim. + buffer) at dilutions 1:12 to 1:3; (ii) Con A-supernatant + HRF (Con $A+H R F)$ vs. unstimulated supernatant + HRF (Unstim. $+H R F)$ at dilutions $1: 96$ to $1: 24$; (iii) Con A-supernatant + HRF $($ Con $A+H R F)$ at dilutions 1:96 to 1:12 vs. buffer + HRF (=30\% \pm 1 mean histamine release); (iv) Unstimulated supernatant + HRF (Unstim. + HRF) at dilutions $1: 12$ to $1: 3$ vs. buffer + HRF. 
tant vs. unstimulated supernatant was significant at dilutions 1:96 to $1: 24, P<0.05$ ). An apparent low inhibitory activity at higher concentrations of Con A-stimulated supernatants (dilutions $1: 6$ and $1: 3$ ) is probably due to the presence of substantial amounts of HRF. Because of the obvious difficulties in assaying both HRF and HRIF in Con A-stimulated supernatants, we conducted chromatographic separation of the two cytokines.

Gel filtration. Gel filtration of histamine-stimulated supernatant revealed a single peak of activity at the $M_{\mathrm{r}}$ range 8-10 kD (Fig. 4 A). Gel chromatography of Con A-pulsed MNC supernatant (Fig. $4 \mathrm{~B}$ ) showed that this material contained both HRF and HRIF activities. HRF was recovered from fractions which corresponded to the $M_{\mathrm{r}}$ ranges of $15-30 \mathrm{kD}$ as well in a larger fraction (previously shown to be $\sim 50 \mathrm{kD}$ ); and HRIF appeared in the $M_{\mathrm{r}}$ range of 8-10 kD. Histamine-stimulated supernatant from MNC of some normal donors also showed a small peak of HRF in the range of $15-30 \mathrm{kD}$.

Physicochemical characterization of HRIF. Histaminestimulated MNC supernatants were used for physicochemical characterization of HRIF. Enzymatic treatment of HRIF-containing supernatants with trypsin and chymotrypsin almost completely abolished its activity (Table I). This suggested that intact protein structure is necessary for the inhibitory activity of HRIF. Treatment of HRIF-containing supernatant with neuraminidase did not affect its activity. When buffer was

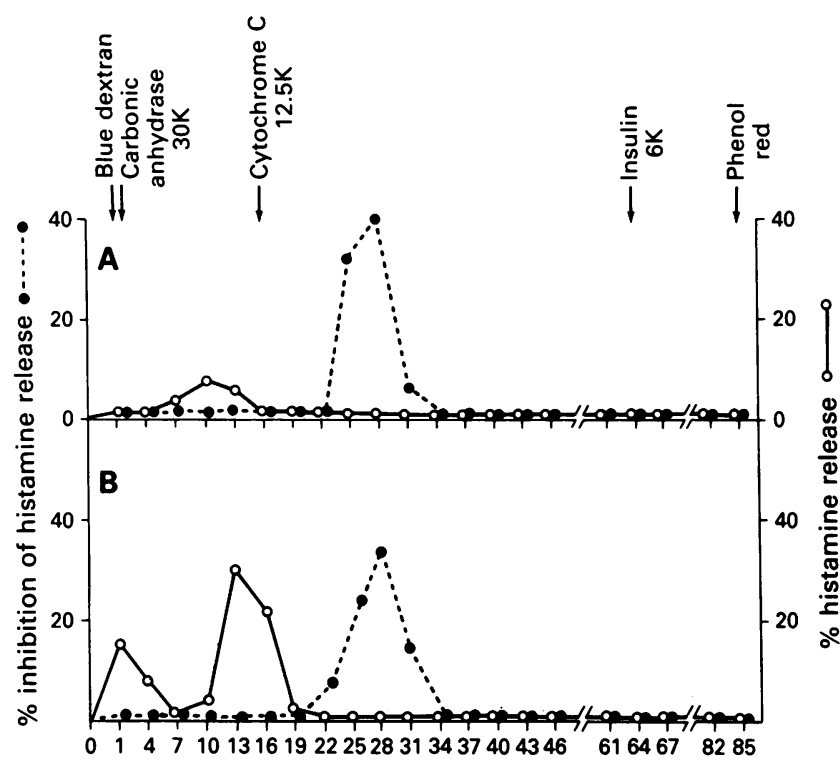

Figure 4. Gel chromatography of histamine-stimulated $(A)$ and Con A-stimulated $(B)$ MNC supernatants. 15-fold concentrated supernatant $(2 \mathrm{ml})$ was applied to a column $(90 \times 1.5 \mathrm{~cm})$ that was precalibrated with marker proteins. 1-ml fractions were collected, and every third fraction was tested at a dilution 1:3 for inhibition of HRF-induced histamine release from basophils. HRIF activity (๑) of histamine-stimulated supernatant appeared in the fractions that corresponded to the $M_{\mathrm{r}}$ range of 8-10 kD. A small peak of HRF (O) was found in the 15-30-kD range. This experiment was repeated twice, and a similar elution profile of HRIF was noted. Gel filtration of Con A-stimulated mononuclear cell supernatant from healthy donors showed HRIF activity in the region corresponding to $M_{\mathrm{r}}$ 8-10 kD whereas HRF activity appeared in the void volume $\left(M_{\mathrm{r}}\right.$ $>30 \mathrm{kD}$ ) and in the $M_{\mathrm{r}}$ range of $15-30 \mathrm{kD}$. This experiment was repeated twice, and similar results were obtained. Control histamine release ranged from $26 \%$ to $48 \%$.
Table I. Physicochemical Characterization of HRIF

\begin{tabular}{|c|c|c|}
\hline Treatment & $\begin{array}{c}\text { Inhibition of } \\
\text { histamine release (\%) }\end{array}$ & $P^{\prime \prime}$ \\
\hline Untreated HRIF* & $61 \pm 9$ & \\
\hline HRIF, $60^{\circ} \mathrm{C} 1 \mathrm{~h}$ & $59 \pm 9$ & $>0.5$ \\
\hline HRIF $\times 4$ freezing and thawing & $48 \pm 11$ & $>0.5$ \\
\hline HRIF + trypsin ${ }^{\ddagger}$ & $11 \pm 9$ & 0.001 \\
\hline HRIF + chymotrypsin ${ }^{\ddagger}$ & 0 & 0.001 \\
\hline HRIF + neuraminidase ${ }^{\S}$ & $43 \pm 7$ & $>0.5$ \\
\hline
\end{tabular}

Values for inhibition of histamine release given as mean \pm SEM.

* Untreated controls of HRIF for enzyme-treated experiments were dialyzed against $\mathrm{HCM}, \mathrm{pH} 7.8$, and then incubated at $30^{\circ} \mathrm{C}$ for trypsin and chymotrypsin experiments or dialyzed against acetate buffer, pH 5, and then incubated at $37^{\circ} \mathrm{C}$ for neuraminidase experiments for $2 \mathrm{~h}$. These treatments did not affect the activity of the supernatants. ${ }^{\ddagger}$ HRIF was dialyzed against HCM, pH 7.8 and then incubated at $30^{\circ} \mathrm{C}$ for $2 \mathrm{~h}$. Results of four duplicate experiments are shown. ${ }^{\S} \mathrm{HRIF}$ was dialyzed against acetate buffer, $\mathrm{pH} 5$, and then incubated with neuraminidase in the same buffer at $37^{\circ} \mathrm{C}$ for $2 \mathrm{~h}$. $(N=3$ for neuraminidase experiments, and the mean control inhibition by untreated supernatants in these experiments was $54 \pm 8 \%$.)

"Wilcoxon's rank sum test.

incubated with these enzymes (no HRIF) and then tested, it did not release any histamine from basophils, nor did it affect the response to HRF. HRIF is heat-stable at $56^{\circ} \mathrm{C}$ and fairly resists $\times 4$ freezing and thawing.

In attempting to separate HRF and HRIF by affinity chromatography using lentil lectin-Sepharose and peanut agglutinin-agarose, we found neither molecule bound to these lectincoupled gels and both activities were recovered from the effluents (data not shown).

A preincubation period of 5-10 min with basophils is necessary for complete inhibitory activity (Fig. 5). Preincubation of basophils with HRIF for $<5$ min resulted in less inhibition of histamine release.

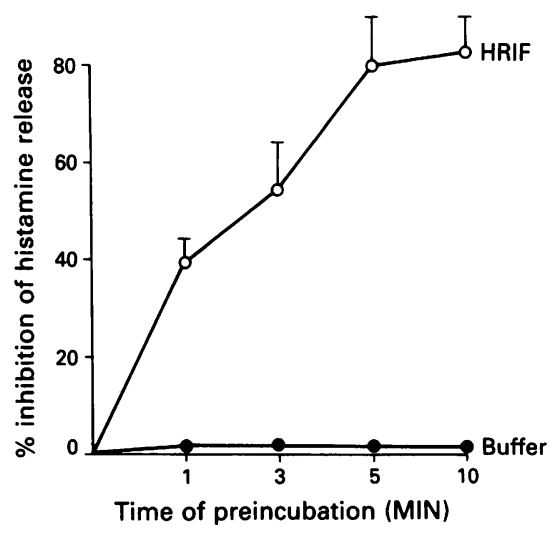

Figure 5. Effect of preincubation period of cells upon the activity of HRIF. Basophil leukocytes were preincubated with HRIF (15-fold concentrated histamine-stimulated supernatant, o) for 40-60 s, 3, 5, and $10 \mathrm{~min}$ at room temperature and then challenged with HRF. Buffer (๑) was used in the control experiments. Maximum inhibition occurred when the cells were preincubated with HRIF for 5 min or more. Results are mean \pm SEM of six experiments. Control histamine release ranged from $18 \%$ to $30 \%$. 
We also studied the effect of removal of HRIF after preincubation upon HRF-induced histamine release from basophils. Leukocytes were preincubated with HRIF for $10 \mathrm{~min}$ then centrifuged and washed twice against $40 \mathrm{vol}$ of buffer and then challenged with HRF. In six experiments, the inhibition of histamine release was $60 \pm 4 \%$ which was not significantly different from that released by the unwashed cells $(64 \pm 3 \%, P$ $>0.5$, Student's $t$ test).

We wondered whether HRIF binds to HRF in the fluid phase and thereby inhibits histamine release. To address this issue, we preincubated HRIF with HRF for $10 \mathrm{~min}$ and then added cells. There was no inhibition of histamine release in these experiments $(n=6)$. In contrast, the same batch of HRIF inhibited histamine release by $64 \pm 3 \%$ when preincubated with basophils for $5 \mathrm{~min}$ before the addition of HRF.

Specificity of HRIF. The inhibitory activity of HRIF towards other agonists was also evaluated. Basophils were preincubated with histamine-stimulated supernatants and then challenged with ragweed antigen, anti-IgE, Con A, PMA, and C5a. We found that HRIF did not inhibit histamine release from basophils induced with these agents (Fig. 6).

\section{Discussion}

The results presented in this paper demonstrate that MNC from healthy subjects produce a HRIF upon stimulation with histamine or the mitogen Con A. HRIF specifically inhibits HRF-induced histamine release from basophils. Other basophil secretagogues-ragweed pollen allergens, anti-IgE, Con A, PMA (a protein kinase $\mathrm{C}$ activator), and the anaphylatoxin C5a-are not blocked by HRIF. Inhibition of histamine release by HRIF requires preincubation with basophils for 5-10 min. Removal of HRIF by washing after the preincubation period does not affect the inhibition of histamine release. HRIF is a heat-stable, trypsin- and chymotrypsin-sensitive, and neuraminidase-resistant protein of apparent $M_{\mathrm{r}} 8-10 \mathrm{kD}$. HRIF is distinct from interleukins 1,2 , and 4 and $\gamma$-interferon, since these cytokines did not inhibit the release of histamine

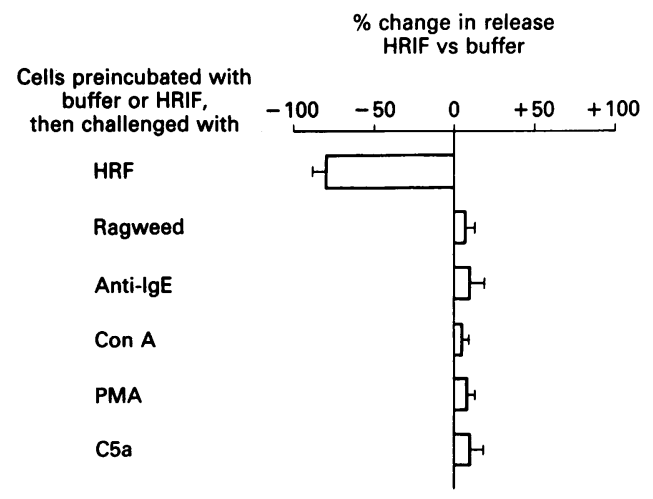

Figure 6. Effect of HRIF on histamine release by various secretagogues. Basophils from ragweed sensitive donors were preincubated with HRIF-containing supernatant (final dilution of $1: 6$ ) for $5 \mathrm{~min}$, then challenged with HRF, ragweed allergen $\left(10^{-6} \mathrm{wt} / \mathrm{vol}\right)$, anti-IgE $(1: 10,000)$, Con A $(10 \mu \mathrm{g} / \mathrm{ml})$, PMA $(10 \mathrm{ng} / \mathrm{ml})$, and C5a (1:100). Results (mean \pm SEM) from six experiments are shown in the figure. HRIF significantly inhibited HRF-induced histamine release but failed to affect histamine release by allergen, anti-IgE, Con A, PMA, and $\mathrm{C} 5 \mathrm{a}$. Control histamine release in these experiments ranged from $30 \%$ to $60 \%$. when tested at concentrations in a range of $0.05-500 \mathrm{U} / \mathrm{ml}$ (data not shown).

Histamine inhibits antigen-induced histamine release from basophils at concentrations of $3 \times 10^{-7}$ to $10^{-6} \mathrm{M}(22)$. We do not think that inhibition of HRF-induced histamine release was due to the presence of contaminating histamine in the supernatant because histamine was undetectable in the dialyzed supernatants $\left(<10^{-9} \mathrm{M}\right)$. Furthermore, HRIF did not inhibit antigen-induced histamine release in our experiments.

One of the major problems that we encountered in assaying HRIF was the presence of HRF in most MNC supernatants. We have overcome this problem by stimulating the cells with histam.ne, which inhibits the production of HRF and stimulates the production of HRIF. Additionally, we noticed that HRF activity was easily diluted to insignificant effects at 1:12, whereas HRIF was most active at these dilutions. Another way to separate these cytokines is gel chromatography with Sephadex G-50.

It has been well established that histamine has immunomodulatory properties. T and B lymphocytes and monocytes possess both $\mathrm{H}_{1}$ and $\mathrm{H}_{2}$ receptors. Histamine stimulates the production of several lymphokines (reviewed by Beer et al. [18]) including the histamine-induced suppressor factor, lymphocyte chemotactic factor, and migration inhibitory factor for lymphocytes. HRIF appears to be distinct from these lymphokines by virtue of its lower $M_{\mathrm{r}}$, not being a glycoprotein, and insensitivity to heating at $56^{\circ} \mathrm{C}$. Above all, the production of histamine-induced suppressor factor, lymphocyte chemotactic factor, and migration inhibitory factor for lymphocytes requires high concentrations of histamine, usually in the range of $10^{-5}$ to $10^{-3} \mathrm{M}$ whereas the optimal range for HRIF synthesis is $10^{-8}$ to $10^{-6} \mathrm{M}$. We think the low concentration of histamine needed to stimulate synthesis of HRIF bodes well for the physiologic significance of this cytokine. Whether HRIF possesses other biological activities remains to be determined in future studies.

Studies from several laboratories have established that HRF are cytokines that release histamine and leukotrienes from basophils and mast cells $(5-8,23-31)$. HRF are produced by several cells, including MNC, lung macrophages, neutrophils, and platelets. Our recent studies have shown that B cells are the major producer of HRF recovered from MNC supernatant, although other cells such as $\mathrm{CD}^{+} \mathrm{T}$ cells synthesize moderate amounts of HRF (9). Recently, it has been shown that a HRF-like substance is produced by two-cell human embryo in culture (32). Although the significance of this finding is not clear, it has been speculated that the release of histamine by HRF might favor implantation of the embryo. Since HRF are produced by so many different cell types, we believe they may have considerable biologic importance. Consequently, a specific inhibitor of HRF might have a major role in regulating the activation of basophils and mast cells.

Production of HRIF by MNC suggests that these cells not only stimulate the function of basophils and mast cells but also inhibit their activity. Stimulation of HRIF production by histamine is another example of the negative feedback mechanisms that exist between lymphocytes and histamine containing cells. Lymphocytes produce HRF that activate mast cells and basophils. Histamine released from the target cells stimulates lymphocytes to synthesize HRIF, which, in turn, inhibits further histamine release, and the immunologic homeostasis is restored. We speculate that a fine balance exists between the 
production of HRF and HRIF in vivo and loss of this balance may contribute to the development of disease.

Some recent data suggest that this concept might be true for asthmatic patients. Relatively large amounts of HRF are produced spontaneously by MNC from asthmatic patients (33). This spontaneous HRF production highly correlates with the severity of bronchial hyperreactivity (34) and clinical symptoms (35). HRF-like molecules have been recovered from skin blister fluid during late-phase allergic reactions (36), and it has been speculated that HRF might be involved in the development of late-phase reactions. The late allergic reaction is now considered the most important factor in the pathogenesis of chronic asthma. Since HRIF specifically inhibits HRF activity, the production of HRIF might represent a protective mechanism against the development of late allergic reactions and by inference, chronic asthma.

Although synthesis of IgE antibody seems to be a necessary condition for initiation of allergic disease, it may not be sufficient. It has been suggested that the synthesis of HRF is an equally important phenomenon in predisposing individuals to atopy (34-38). We propose that specific inhibition of HRF by the endogenous cytokine HRIF may be an important physiologic mechanism for regulating basophils and mast cells. HRIF may be one of the major molecules preventing allergic hypersensitivity, and administration of exogenous HRIF might prove useful for reversing allergic reactions.

\section{Acknowledgments}

We appreciate the expert technical assistance of Lisa Robinson, Wil Saito, Jody Welter, and Patricia Forsythe, and the editorial assistance of Alice Chulo. The authors are grateful to Ethel Patten, M.D., Director, University of Texas of Medical Branch Blood Bank, for providing leukocyte concentrates for the production of HRF.

This study was supported in part by grants from the National Institute of Allergy and Infectious Diseases, National Institutes of Health AI-22940, and from the James B. McLaughlin Fund.

\section{References}

1. Ihle, J. N., J. Keller, S. Oroszlan, L. E. Henderson, T. D. Copeland, F. Fitch, M. B. Prystowsky, E. Goldwasser, J. W. Schrader, E. Palaszynski, M. Dy, and B. Lebel. 1982. Biologic properties of homogeneous interleukin 3. I. Demonstration of WEHI-3 growth factor activity, mast cell growth factor activity, $P$ cell stimulating factor activity, colony stimulating factor activity, and histamine producing cell stimulating activity. J. Immunol. 131:282-287.

2. Smith, C. A., and D. M. Rennick. 1986. Characterization of murine lymphokine distinct from interleukin 2 and interleukin 3 possessing a $T$ cell growth factor activity and a mast cell growth factor activity that synergizes with IL-3. Proc. Natl. Acad. Sci. USA. 83:1857-1863.

3. Stadler, B. M., K. Hirao, K. Todokoro, and A. L. De Weck. 1985. Distinction of the human basophil promoting activity from human interleukin 3. Int. Arch. Allergy Appl. Immunol. 77:151-154.

4. Dvorak, H. F., M. C. Mihm, A. M. Dvorak, R. A. Johnson, E. J. Manseau, E. Morgan, and R. B. Colvin. 1974. Morphology of delayed type hypersensitivity reactions in man. I. Quantative description of the inflammatory response. Lab. Invest. 31:111-130.

5. Thueson, D. O., L. S. Speck, M. A. Lett-Brown, and J. Grant. 1979. Histamine releasing activity (HRA). I. Production by mitogenor antigen-stimulated human mononuclear cells. J. Immunol. 123:626-632.

6. Schulman, E. S., M. C. Liu, D. Proud, D. W. MacGlashan, L. M. Lichtenstein, and M. Plaut. 1985. Human lung macrophages induce histamine release from basophils and mast cells. Am. Rev. Respir. Dis. 131:230-235.

7. Lett-Brown, M. A., D. O. Thueson, D. E. Plank, M. E. Langford, and J. A. Grant. 1984. Histamine releasing activity. IV. Molecular heterogeneity of the activity from stimulated human thoracic duct lymphocytes. Cell. Immunol. 87:434-444.

8. Kaplan, A. P., M. Haak-Frendscho, A. Fauci, C. Dinarello, and E. Halbert. 1985. A histamine releasing factor from activated human mononuclear cells. J. Immunol. 135:2027-2032.

9. Alam, R., M. A. Lett-Brown, and J. A. Grant. 1988. Cellular origin of histamine releasing factor (HRF) produced by mononuclear cells. Ann. Allergy. 60:163. (Abstr.)

10. Ptak, W., P. W. Askenase, R. W. Rosenstein, and R. K. Gershon. 1982. Transfer of an antigen-specific immediate hypersensitivity like reaction with an antigen-binding factor produced by $\mathrm{T}$ cells. Proc. Natl. Acad. Sci. USA. 79:1969-1973.

11. Tadamura, T., A. L. Kuhner, R. R. Rich, J. R. David, and C. W. Pierce. 1976. Biological expressions of lymphocyte activation. V. Characterization of a soluble immune response suppressor (SIRS) produced by Con A-activated spleen cells. J. Immunol. 117:323-330.

12. Namba, Y., B. U. Jegasothy, and B. H. Waksman. 1977. Regulatory substances produced by lymphocytes. V. Production of inhibitor of DNA synthesis by proliferating T lymphocytes. J. Immunol. 118:1379-1384.

13. Bacigalupo, A., M. Podesto, M. C. Mingari, L. Moretta, M. T. Van Lint, and A. Marmont. 1980. Immune suppression of hematopoiesis in aplastic anemia. Activity of T-gamma lymphocytes. J. Immunol. 125:1449-1453.

14. Honda, M., C. Chan, and E. M. Shevach. 1985. Characterization and partial purification of interleukin 2 inhibitor. J. Immunol. 135:1834-1839.

15. Hirashima, M., K. Tashiro, and H. Hayashi. 1984. The regulation of tissue eosinophilia. I. Coexistence of eosinophil chemotactic factor and inhibitor in allergic skin lesions of FCA-treated guinea-pigs. Immunology. 51:441-450.

16. Ishizaka, K. 1985. Twenty years with IgE: from the identification of IgE to regulatory factors for the IgE response. J. Immunol. 135:1-10.

17. Alam, R., D. M. Lewis, and S. A. Olenchock. 1987. Induction of histamine releasing factor synthesis (HRF) synthesis in guinea-pigs. Simultaneous production of a histamine release inhibitory factor (HRIF) and an inhibitor of HRF synthesis (IHS) by lymphocytes. Fed. Proc. 46:928. (Abstr.)

18. Beer, D. J., S. M. Matloff, and R. E. Rocklin. 1984. The influence of histamine on immune and inflammatory responses. $\mathrm{Adv}$. Immunol. 35:209-268.

19. Farnam, J., J. A. Grant, M. A. Lett-Brown, C. Hunt, D. O. Thueson, and P. C. Giclas. 1985. Complement- and IgE-mediated release of histamine from basophils in vitro. V. Differential effects of drugs modulating arachidonic acid metabolism. J. Immunol. 134:541-547.

20. Siraganian, R. P. 1975. Refinements in the automated fluorometric histamine analysis system. J. Immunol. Methods. 7:283-290.

21. Yodoi, J., M. Hirashima, and K. Ishizaka. 1982. Regulatory role of IgE-binding factors from rat $\mathrm{T}$ lymphocytes. $\mathrm{V}$. The carbohydrate moieties in IgE-potentiating factors and IgE-suppressive factors. J. Immunol. 128:289.

22. Bourne, H. R., K. L. Melmon, and L. M. Lichtenstein. 1971. Histamine augments leukocyte adenosine 3 ',5'-monophosphate and blocks antigenic histamine release. Science (Wash. DC). 173:743-745.

23. Thueson, D. O., L. S. Speck, M. A. Lett-Brown, and J. A. Grant. 1979. Histamine releasing factor (HRA). II. Interaction with basophils and physicochemical characterization. J. Immunol. 123:633-639.

24. Sedgwick, J. D., P. G. Holt, and K. J. Turner. 1981. Production of a histamine releasing lymphokine by antigen- and mitogen-stimulated human peripheral T cell. Clin. Exp. Immunol. 45:409-418.

25. Ezeamuzie, J. C., and E. S. K. Assem. 1983. A study of hista- 
mine release from basophils by products of lymphocyte stimulation. Agents Actions. 13:222-230.

26. Goetzl, E. J., D. W. Foster, and P. G. Payan. 1984. A basophil activating factor from human T cells. Immunology. 53:227-234.

27. Alam, R., J. Rozniecki, and K. Selmaj. 1984. A mononuclear cell-derived histamine releasing factor in asthmatic patients. Histamine release from basophils in vitro. Ann. Allergy. 53:66-69.

28. Dvorak, A. M., M. A. Lett-Brown, D. O. Thueson, K. Pyne, P. K. Raghuprasad, S. J. Galli, and J. A. Grant. 1984. Histamine releasing activity (HRA). III. HRA induces human basophil histamine release by provoking noncytotoxic granule exocytosis. Clin. Immunol. Immunopathol. 32:142-150.

29. White, M. V., and M. A. Kaliner. 1987. Neutrophils and mast cells. I. Human neutrophil-derived histamine releasing activity. J. Immunol. 139:1624-1630.

30. Orchard, M. A., A. Kagey-Sobotka, D. Proud, and L. M. Lichtenstein. 1986. Basophil histamine release induced by a substance from stimulated human platelets. J. Immunol. 136:2240-2244.

31. Grant, J. A., M. A. Lett-Brown, J. A. Warner, M. Plaut, L. M. Lichtenstein, M. Haak-Frendscho, and A. P. Kaplan. 1986. Activation of basophils. Fed. Proc. 45:2653-2658.

32. Cochiara, R., G. di Trapani, A. Azzolina, G. Albeggiani, and D. Geraci. 1987. Isolation of histamine releasing factor from two-cell human embryo. Int. Arch. Allergy Appl. Immunol. 84:321-323.
33. Alam, R., J. Rozniecki, and B. Kuzminska. 1985. A mononuclear cell-derived histamine releasing factor (HRF) in asthmatic patients. III. Further studies. Ann. Allergy. 55:825-829.

34. Alam, R., P. Kuna, J. Rozniecki, and B. Kuzminska. 1987. The magnitude of spontaneous production of histamine releasing factor (HRF) by lymphocytes in vitro highly correlates with state of bronchial hyperreactivity in patients with asthma. J. Allergy Clin. Immunol. 79:103-108.

35. Kuna, P., R. Alam, B. Kuzminska, and J. Rozniecki. 1988. The effect of preseasonal immunotherapy on the production of histamine releasing factor (HRF) by mononuclear cells from patients with seasonal asthma. Results of a double-blind placebo-controlled randomized study. J. Allergy Clin. Immunol. 81:291. (Abstr.)

36. Warner, J. A., M. Pienkowski, M. Plaut, P. S. Norman, and L. M. Lichtenstein. 1986. Identification of histamine releasing factor(s) in the late phase of cutaneous IgE-mediated reactions. J. Immunol. 136:2583-2587.

37. Lichtenstein, L. M. 1988. Histamine releasing factors and $\operatorname{lgE}$ heterogeneity. J. Allergy Clin. Immunol. 81:814-820.

38. MacDonald, S. M., L. M. Lichtenstein, D. Proud, M. Plaut, R. M. Naclerio, D. W. MacGlashan, and A. Kagey-Sobotka. 1987. Studies of IgE-dependent histamine releasing factors: heterogeneity of IgE. J. Immunol. 139:506-521. 